\title{
WEIGHTED INTEGRAL INEQUALITIES OF OSTROWSKI, ČEBYŠEV AND LUPAŞ TYPE WITH APPLICATIONS
}

\author{
SILVESTRU SEVER DRAGOMIR ${ }^{1,2}$
}

\begin{abstract}
In this paper we establish some weighted integral inequalities of Ostrowski, Čebyšev and Lupaş type. Applications for continuous probability density functions supported on infinite intervals with two examples are also given.
\end{abstract}

\section{Introduction}

For two Lebesgue integrable functions $f, g:[a, b] \rightarrow \mathbb{R}$, consider the $\check{C}$ ebyšev functional:

$$
C(f, g):=\frac{1}{b-a} \int_{a}^{b} f(t) g(t) d t-\frac{1}{(b-a)^{2}} \int_{a}^{b} f(t) d t \int_{a}^{b} g(t) d t .
$$

In 1935, Grüss [17] showed that

$$
|C(f, g)| \leq \frac{1}{4}(M-m)(N-n),
$$

provided that there exists the real numbers $m, M, n, N$ such that

$$
m \leq f(t) \leq M \quad \text { and } \quad n \leq g(t) \leq N \quad \text { for a.e. } t \in[a, b] .
$$

The constant $\frac{1}{4}$ is best possible in (1.1) in the sense that it cannot be replaced by a smaller quantity.

Another, however less known result, even though it was obtained by Čebyšev in 1882 , [4], states that

$$
|C(f, g)| \leq \frac{1}{12}\left\|f^{\prime}\right\|_{\infty}\left\|g^{\prime}\right\|_{\infty}(b-a)^{2},
$$

provided that $f^{\prime}, g^{\prime}$ exist and are continuous on $[a, b]$ and $\left\|f^{\prime}\right\|_{\infty}=\sup _{t \in[a, b]}\left|f^{\prime}(t)\right|$. The constant $\frac{1}{12}$ cannot be improved in the general case.

The Čebyšev inequality (1.4) also holds if $f, g:[a, b] \rightarrow \mathbb{R}$ are assumed to be absolutely continuous and $f^{\prime}, g^{\prime} \in L_{\infty}[a, b]$ while $\left\|f^{\prime}\right\|_{\infty}=\operatorname{essup}_{t \in[a, b]}\left|f^{\prime}(t)\right|$.

A mixture between Grüss' result (1.2) and Čebyšev's one (1.4) is the following inequality obtained by Ostrowski in 1970, [24]:

$$
|C(f, g)| \leq \frac{1}{8}(b-a)(M-m)\left\|g^{\prime}\right\|_{\infty},
$$

provided that $f$ is Lebesgue integrable and satisfies (1.3) while $g$ is absolutely continuous and $g^{\prime} \in L_{\infty}[a, b]$. The constant $\frac{1}{8}$ is best possible in (1.5).

1991 Mathematics Subject Classification. 26D15; 26D10.

Key words and phrases. Ostrowski's inequality, Čebyšev inequality, Lupaş inequality, Weighted integrals, Probability density functions, Cumulative probability function. 
The case of euclidean norms of the derivative was considered by A. Lupaş in [21] in which he proved that

$$
|C(f, g)| \leq \frac{1}{\pi^{2}}\left\|f^{\prime}\right\|_{2}\left\|g^{\prime}\right\|_{2}(b-a),
$$

provided that $f, g$ are absolutely continuous and $f^{\prime}, g^{\prime} \in L_{2}[a, b]$. The constant $\frac{1}{\pi^{2}}$ is the best possible.

Consider now the weighted Čebyšev functional

$$
\begin{aligned}
& C_{w}(f, g):=\frac{1}{\int_{a}^{b} w(t) d t} \int_{a}^{b} w(t) f(t) g(t) d t \\
& \quad-\frac{1}{\int_{a}^{b} w(t) d t} \int_{a}^{b} w(t) f(t) d t \frac{1}{\int_{a}^{b} w(t) d t} \int_{a}^{b} w(t) g(t) d t
\end{aligned}
$$

where $f, g, w:[a, b] \rightarrow \mathbb{R}$ and $w(t) \geq 0$ for a.e. $t \in[a, b]$ are measurable functions such that the involved integrals exist and $\int_{a}^{b} w(t) d t>0$.

In [6], Cerone and Dragomir obtained, among others, the following inequalities:

$$
\begin{aligned}
&\left|C_{w}(f, g)\right| \\
& \leq \frac{1}{2}(M-m) \frac{1}{\int_{a}^{b} w(t) d t} \int_{a}^{b} w(t)\left|g(t)-\frac{1}{\int_{a}^{b} w(s) d s} \int_{a}^{b} w(s) g(s) d s\right| d t \\
& \leq \frac{1}{2}(M-m)\left[\left.\frac{1}{\int_{a}^{b} w(t) d t} \int_{a}^{b} w(t)\left|g(t)-\frac{1}{\int_{a}^{b} w(s) d s} \int_{a}^{b} w(s) g(s) d s\right| d t\right|^{\frac{1}{p}}\right. \\
& \leq \frac{1}{2}(M-m) \operatorname{essup}_{t \in[a, b]}\left|g(t)-\frac{1}{\int_{a}^{b} w(s) d s} \int_{a}^{b} w(s) g(s) d s\right|
\end{aligned}
$$

for $p>1$, provided $-\infty<m \leq f(t) \leq M<\infty$ for a.e. $t \in[a, b]$ and the corresponding integrals are finite. The constant $\frac{1}{2}$ is sharp in all the inequalities in (1.8) in the sense that it cannot be replaced by a smaller constant.

In addition, if $-\infty<n \leq g(t) \leq N<\infty$ for a.e. $t \in[a, b]$, then the following refinement of the celebrated Grüss inequality is obtained:

$$
\begin{array}{r}
\leq \frac{1}{2}(M-m) \frac{1}{\int_{a}^{b} w(t) d t} \int_{a}^{b} w(t)\left|g(t)-\frac{1}{\int_{a}^{b} w(s) d s} \int_{a}^{b} w(s) g(s) d s\right| d t \\
\leq \frac{1}{2}(M-m)\left[\frac{1}{\int_{a}^{b} w(t) d t} \int_{a}^{b} w(t)\left|g(t)-\frac{1}{\int_{a}^{b} w(s) d s} \int_{a}^{b} w(s) g(s) d s\right|^{2} d t\right]^{\frac{1}{2}} \\
\leq \frac{1}{4}(M-m)(N-n) .
\end{array}
$$$$
\left|C_{w}(f, g)\right|
$$

Here, the constants $\frac{1}{2}$ and $\frac{1}{4}$ are also sharp in the sense mentioned above.

For other inequality of Grüss' type see [1]-[5], [7]-[16], [18]-[23] and [25]-[28].

Motivated by the above results, in this paper we establish some weighted integral inequalities of Ostrowski, Čebyšev and Lupaş type. Applications for continuous 
probability density functions supported on infinite intervals with two examples are also given.

\section{Weighted Inequalities}

We can define, as above

$$
\begin{aligned}
C_{h^{\prime}}(f, g):= & \frac{1}{h(b)-h(a)} \int_{a}^{b} f(t) g(t) h^{\prime}(t) d t \\
& -\frac{1}{h(b)-h(a)} \int_{a}^{b} f(t) h^{\prime}(t) d t \frac{1}{h(b)-h(a)} \int_{a}^{b} g(t) h^{\prime}(t) d t,
\end{aligned}
$$

where $h$ is absolutely continuous and $f, g$ are Lebesgue measurable on $[a, b]$ and such that the above integrals exist.

The following weighted version of Ostrowski's inequality holds:

Theorem 1. Let $h:[a, b] \rightarrow[h(a), h(b)]$ be a continuous strictly increasing function that is differentiable on $(a, b)$. If $f$ is Lebesgue integrable and satisfies the condition $m \leq f(t) \leq M$ for $t \in[a, b]$ and $g:[a, b] \rightarrow \mathbb{R}$ is absolutely continuous on $[a, b]$ and $\frac{g^{\prime}}{h^{\prime}}$ is essentially bounded, namely $\frac{g^{\prime}}{h^{\prime}} \in L_{\infty}[a, b]$, then we have

$$
\left|C_{h^{\prime}}(f, g)\right| \leq \frac{1}{8}[h(b)-h(a)](M-m)\left\|\frac{g^{\prime}}{h^{\prime}}\right\|_{[a, b], \infty} .
$$

The constant $\frac{1}{8}$ is best possible.

Proof. Assume that $[c, d] \subset[a, b]$. If $g:[c, d] \rightarrow \mathbb{C}$ is absolutely continuous on $[c, d]$, then $g \circ h^{-1}:[h(c), h(d)] \rightarrow \mathbb{C}$ is absolutely continuous on $[h(c), h(d)]$ and using the chain rule and the derivative of inverse functions we have

$$
\left(g \circ h^{-1}\right)^{\prime}(z)=\left(g^{\prime} \circ h^{-1}\right)(z)\left(h^{-1}\right)^{\prime}(z)=\frac{\left(g^{\prime} \circ h^{-1}\right)(z)}{\left(h^{\prime} \circ h^{-1}\right)(z)}
$$

for almost every (a.e.) $z \in[h(c), h(d)]$.

If $x \in[c, d]$, then by taking $z=h(x)$, we get

$$
\left(g \circ h^{-1}\right)^{\prime}(z)=\frac{\left(g^{\prime} \circ h^{-1}\right)(h(x))}{\left(h^{\prime} \circ h^{-1}\right)(h(x))}=\frac{g^{\prime}(x)}{h^{\prime}(x)} .
$$

Therefore, since $\frac{g^{\prime}}{h^{\prime}} \in L_{\infty}[c, d]$, hence $\left(g \circ h^{-1}\right)^{\prime} \in L_{\infty}[h(c), h(d)]$. Also

$$
\left\|\left(g \circ h^{-1}\right)^{\prime}\right\|_{[h(c), h(d)], \infty}=\left\|\frac{g^{\prime}}{h^{\prime}}\right\|_{[c, d], \infty}
$$

Now, if we use the Ostrowski's inequality (1.5) for the functions $f \circ h^{-1}$ and $g \circ h^{-1}$ on the interval $[h(a), h(b)]$, then we get

$$
\begin{aligned}
& \mid \frac{1}{h(b)-h(a)} \int_{h(a)}^{h(b)} f \circ h^{-1}(u) g \circ h^{-1}(u) d u \\
& -\frac{1}{[h(b)-h(a)]^{2}} \int_{h(a)}^{h(b)} f \circ h^{-1}(u) d u \int_{h(a)}^{h(b)} g \circ h^{-1}(u) d u \mid \\
& \leq \frac{1}{8}[h(b)-h(a)](M-m)\left\|\left(g \circ h^{-1}\right)^{\prime}\right\|_{[h(a), h(b)], \infty}
\end{aligned}
$$


since $m \leq f \circ h^{-1}(u) \leq M$ for all $u \in[h(a), h(b)]$.

Observe also that, by the change of variable $t=h^{-1}(u), u \in[g(a), g(b)]$, we have $u=h(t)$ that gives $d u=h^{\prime}(t) d t$ and

$$
\begin{aligned}
\int_{h(a)}^{h(b)}\left(f \circ h^{-1}\right)(u) d u & =\int_{a}^{b} f(t) h^{\prime}(t) d t, \\
\int_{h(a)}^{h(b)} g \circ h^{-1}(u) d u & =\int_{a}^{b} g(t) h^{\prime}(t) d t, \\
\int_{h(a)}^{h(b)} f \circ h^{-1}(u) g \circ h^{-1}(u) d u & =\int_{a}^{b} f(t) g(t) h^{\prime}(t) d t
\end{aligned}
$$

and

$$
\left\|\left(g \circ h^{-1}\right)^{\prime}\right\|_{[h(a), h(b)], \infty}=\left\|\frac{g^{\prime}}{h^{\prime}}\right\|_{[a, b], \infty} .
$$

By making use of (2.4) we then get the desired result (2.2).

The best constant follows by Ostrowski's inequality (1.5).

If $w:[a, b] \rightarrow \mathbb{R}$ is continuous and positive on the interval $[a, b]$, then the function $W:[a, b] \rightarrow[0, \infty), W(x):=\int_{a}^{x} w(s) d s$ is strictly increasing and differentiable on $(a, b)$. We have $W^{\prime}(x)=w(x)$ for any $x \in(a, b)$.

Corollary 1. Assume that $w:[a, b] \rightarrow(0, \infty)$ is continuous on $[a, b], f$ is Lebesgue integrable and satisfies the condition $m \leq f(t) \leq M$ for $t \in[a, b]$ and $g:[a, b] \rightarrow$ $\mathbb{R}$ is absolutely continuous on $[a, b]$ with $\frac{g^{\prime}}{w}$ is essentially bounded, namely $\frac{g^{\prime}}{w} \in$ $L_{\infty}[a, b]$, then we have

$$
\left|C_{w}(f, g)\right| \leq \frac{1}{8}(M-m)\left\|\frac{g^{\prime}}{w}\right\|_{[a, b], \infty} \int_{a}^{b} w(s) d s .
$$

The constant $\frac{1}{8}$ is best possible.

Remark 1. Under the assumptions of Corollary 1 and if there exists a constant $K>0$ such that $\left|g^{\prime}(t)\right| \leq K w(t)$ for a.e. $t \in[a, b]$, then by (2.5) we get

$$
\left|C_{w}(f, g)\right| \leq \frac{1}{8}(M-m) K \int_{a}^{b} w(s) d s .
$$

We have the following weighted version of Čebyšev inequality:

Theorem 2. Let $h:[a, b] \rightarrow[h(a), h(b)]$ be a continuous strictly increasing function that is differentiable on $(a, b)$. If $f, g:[a, b] \rightarrow \mathbb{R}$ are absolutely continuous on $[a, b]$ and $\frac{f^{\prime}}{h^{\prime}}, \frac{g^{\prime}}{h^{\prime}} \in L_{\infty}[a, b]$, then we have

$$
\left|C_{h^{\prime}}(f, g)\right| \leq \frac{1}{12}[h(b)-h(a)]^{2}\left\|\frac{f^{\prime}}{h^{\prime}}\right\|_{[a, b], \infty}\left\|\frac{g^{\prime}}{h^{\prime}}\right\|_{[a, b], \infty} .
$$

The constant $\frac{1}{12}$ is best possible.

The proof follows by the use of Čebyšev inequality (1.4) for the functions $f \circ h^{-1}$ and $g \circ h^{-1}$ on the interval $[h(a), h(b)]$. 
Corollary 2. Assume that $w:[a, b] \rightarrow(0, \infty)$ is continuous on $[a, b]$. If $f, g:$ $[a, b] \rightarrow \mathbb{R}$ are absolutely continuous on $[a, b]$ and $\frac{f^{\prime}}{w}, \frac{g^{\prime}}{w} \in L_{\infty}[a, b]$, then we have

$$
\left|C_{w}(f, g)\right| \leq \frac{1}{12}\left\|\frac{f^{\prime}}{w}\right\|_{[a, b], \infty}\left\|\frac{g^{\prime}}{w}\right\|_{[a, b], \infty}\left(\int_{a}^{b} w(s) d s\right)^{2} .
$$

The constant $\frac{1}{12}$ is best possible.

Remark 2. Under the assumptions of Corollary 2 and if there exists the constants $K, L>0$ such that $\left|f^{\prime}(t)\right| \leq L w(t),\left|g^{\prime}(t)\right| \leq K w(t)$ for a.e. $t \in[a, b]$, then by (2.8) we get

$$
\left|C_{w}(f, g)\right| \leq \frac{1}{12} L K\left(\int_{a}^{b} w(s) d s\right)^{2} .
$$

We also have the following version of Lupaş inequality:

Theorem 3. Let $h:[a, b] \rightarrow[h(a), h(b)]$ be a continuous strictly increasing function that is differentiable on $(a, b)$. If $f, g:[a, b] \rightarrow \mathbb{R}$ are absolutely continuous on $[a, b]$ and $\frac{f^{\prime}}{\left(h^{\prime}\right)^{1 / 2}}, \frac{g^{\prime}}{\left(h^{\prime}\right)^{1 / 2}} \in L_{2}[a, b]$, then we have

$$
\left|C_{h^{\prime}}(f, g)\right| \leq \frac{1}{\pi^{2}}\left\|\frac{f^{\prime}}{\left(h^{\prime}\right)^{1 / 2}}\right\|_{[a, b], 2}\left\|\frac{g^{\prime}}{\left(h^{\prime}\right)^{1 / 2}}\right\|_{[a, b], 2}[h(b)-h(a)] .
$$

The constant $\frac{1}{\pi^{2}}$ is best possible.

Proof. Using the identity (2.3) above, we have

$$
\int_{h(a)}^{h(b)}\left|\left(g \circ h^{-1}\right)^{\prime}(u)\right|^{2} d u=\int_{h(a)}^{h(b)}\left|\frac{\left(g^{\prime} \circ h^{-1}\right)(u)}{\left(h^{\prime} \circ h^{-1}\right)(u)}\right|^{2} d u .
$$

By the change of variable $t=h^{-1}(u), u \in[h(a), h(b)]$, we have $u=h(t)$ that gives $d u=h^{\prime}(t) d t$. Therefore

$$
\begin{aligned}
\int_{h(a)}^{h(b)}\left|\frac{\left(g^{\prime} \circ h^{-1}\right)(u)}{\left(h^{\prime} \circ h^{-1}\right)(u)}\right|^{2} d u & =\int_{b}^{b}\left|\frac{g^{\prime}(t)}{h^{\prime}(t)}\right|^{2} h^{\prime}(t) d t \\
& =\int_{b}^{b}\left|\frac{g^{\prime}(t)}{\left[h^{\prime}(t)\right]^{1 / 2}}\right|^{2} d t=\left\|\frac{g^{\prime}}{\left(h^{\prime}\right)^{1 / 2}}\right\|_{[a, b], 2}^{2}
\end{aligned}
$$

In a similar way, we also have

$$
\int_{h(a)}^{h(b)}\left|\frac{\left(f^{\prime} \circ h^{-1}\right)(u)}{\left(h^{\prime} \circ h^{-1}\right)(u)}\right|^{2} d u=\left\|\frac{f^{\prime}}{\left(h^{\prime}\right)^{1 / 2}}\right\|_{[a, b], 2}^{2} .
$$


By making use of Lupaş inequality (1.6) for the functions $f \circ h^{-1}$ and $g \circ h^{-1}$ on the interval $[h(a), h(b)]$ we get

$$
\begin{aligned}
& \mid \frac{1}{h(b)-h(a)} \int_{h(a)}^{h(b)} f \circ h^{-1}(u) g \circ h^{-1}(u) d u \\
& -\frac{1}{[h(b)-h(a)]^{2}} \int_{h(a)}^{h(b)} f \circ h^{-1}(u) d u \int_{h(a)}^{h(b)} g \circ h^{-1}(u) d u \mid \\
& \leq \frac{1}{\pi^{2}}\left\|\left(f \circ h^{-1}\right)^{\prime}\right\|_{[h(a), h(b)], 2}\left\|\left(g \circ h^{-1}\right)^{\prime}\right\|_{[h(a), h(b)], 2}[h(b)-h(a)],
\end{aligned}
$$

which together with the above calculations produces the desired result (2.10).

Corollary 3. Assume that $w:[a, b] \rightarrow(0, \infty)$ is continuous on $[a, b]$. If $f, g:$ $[a, b] \rightarrow \mathbb{R}$ are absolutely continuous on $[a, b]$ and $\frac{f^{\prime}}{w^{1 / 2}}, \frac{g^{\prime}}{w^{1 / 2}} \in L_{2}[a, b]$, then we have

$$
\left|C_{w}(f, g)\right| \leq \frac{1}{\pi^{2}}\left\|\frac{f^{\prime}}{w^{1 / 2}}\right\|_{[a, b], 2}\left\|\frac{g^{\prime}}{w^{1 / 2}}\right\|_{[a, b], 2} \int_{a}^{b} w(s) d s .
$$

The constant $\frac{1}{\pi^{2}}$ is best possible.

We can give some examples of interest for several function $h:[a, b] \rightarrow[h(a), h(b)]$ that are continuous strictly increasing functions and differentiable on $(a, b)$.

a). If we take $h:[a, b] \subset(0, \infty) \rightarrow \mathbb{R}, h(t)=\ln t$, in (2.2), then we get for $\ell(t):=t$, that

$$
\left|C_{\ell^{-1}}(f, g)\right| \leq \frac{1}{8}(M-m)\left\|\ell g^{\prime}\right\|_{[a, b], \infty} \ln \left(\frac{b}{a}\right)
$$

where

$$
C_{\ell^{-1}}(f, g):=\frac{1}{\ln \left(\frac{b}{a}\right)} \int_{a}^{b} \frac{f(t) g(t)}{t} d t-\frac{1}{\ln \left(\frac{b}{a}\right)} \int_{a}^{b} \frac{f(t)}{t} d t \frac{1}{\ln \left(\frac{b}{a}\right)} \int_{a}^{b} \frac{g(t)}{t} d t
$$

and provided that $f$ is Lebesgue integrable and satisfies the condition $m \leq f(t) \leq M$ for $t \in[a, b]$ and $g:[a, b] \rightarrow \mathbb{R}$ is absolutely continuous on $[a, b]$ and $\ell g^{\prime} \in L_{\infty}[a, b]$.

If $f, g:[a, b] \rightarrow \mathbb{R}$ are absolutely continuous on $[a, b]$ and $\ell f^{\prime}, \ell g^{\prime} \in L_{\infty}[a, b]$, then by (2.7) we have

$$
\left|C_{\ell^{-1}}(f, g)\right| \leq \frac{1}{12}\left\|\ell f^{\prime}\right\|_{[a, b], \infty}\left\|\ell g^{\prime}\right\|_{[a, b], \infty}\left[\ln \left(\frac{b}{a}\right)\right]^{2}
$$

Also, if $f, g:[a, b] \rightarrow \mathbb{R}$ are absolutely continuous on $[a, b]$ and $\ell^{1 / 2} f^{\prime}, \ell^{1 / 2} g^{\prime} \in$ $L_{2}[a, b]$, then we have by $(2.10)$

$$
\left|C_{\ell^{-1}}(f, g)\right| \leq \frac{1}{\pi^{2}}\left\|\ell^{1 / 2} f^{\prime}\right\|_{[a, b], 2}\left\|\ell^{1 / 2} g^{\prime}\right\|_{[a, b], 2} \ln \left(\frac{b}{a}\right) .
$$

b). If we take $h:[a, b] \subset \mathbb{R} \rightarrow(0, \infty), h(t)=\exp t$, in (2.2), then we get

$$
\left|C_{\exp }(f, g)\right| \leq \frac{1}{8}(M-m)\left\|\frac{g^{\prime}}{\exp }\right\|_{[a, b], \infty}(\exp b-\exp a),
$$


where

$$
\begin{aligned}
C_{\exp }(f, g): & =\frac{1}{\exp b-\exp a} \int_{a}^{b} f(t) g(t) \exp t d t \\
& -\frac{1}{\exp b-\exp a} \int_{a}^{b} f(t) \exp t d t \frac{1}{\exp b-\exp a} \int_{a}^{b} g(t) \exp t d t
\end{aligned}
$$

and provided that $f$ is Lebesgue integrable and satisfies the condition $m \leq f(t) \leq M$ for $t \in[a, b]$ and $g:[a, b] \rightarrow \mathbb{R}$ is absolutely continuous on $[a, b]$ and $\frac{g^{\prime}}{\exp } \in L_{\infty}[a, b]$.

If $f, g:[a, b] \rightarrow \mathbb{R}$ are absolutely continuous on $[a, b]$ and $\frac{f^{\prime}}{\exp }, \frac{g^{\prime}}{\exp } \in L_{\infty}[a, b]$, then by (2.7) we have

$$
\left|C_{\exp }(f, g)\right| \leq \frac{1}{12}\left\|\frac{f^{\prime}}{\exp }\right\|_{[a, b], \infty}\left\|\frac{g^{\prime}}{\exp }\right\|_{[a, b], \infty}(\exp b-\exp a)^{2} .
$$

Also, if $f, g:[a, b] \rightarrow \mathbb{R}$ are absolutely continuous on $[a, b]$ and $\frac{f^{\prime}}{\exp ^{1 / 2}}, \frac{g^{\prime}}{\exp ^{1 / 2}} \in$ $L_{2}[a, b]$, then we have by $(2.10)$ that

$$
\left|C_{\exp }(f, g)\right| \leq \frac{1}{\pi^{2}}\left\|\frac{f^{\prime}}{\exp ^{1 / 2}}\right\|_{[a, b], 2}\left\|\frac{g^{\prime}}{\exp ^{1 / 2}}\right\|_{[a, b], 2}(\exp b-\exp a) .
$$

c). If we take $h:[a, b] \subset(0, \infty) \rightarrow \mathbb{R}, h(t)=t^{r}, r>0$ in (2.2), then we get

$$
\left|C_{r \ell^{r-1}}(f, g)\right| \leq \frac{1}{8 r}\left(b^{r}-a^{r}\right)(M-m)\left\|\ell^{1-r} g^{\prime}\right\|_{[a, b], \infty},
$$

where

$$
\begin{aligned}
C_{r \ell^{r-1}}(f, g):=\frac{r}{b^{r}-a^{r}} & \int_{a}^{b} f(t) g(t) t^{r-1} d t \\
& \quad-\frac{r}{b^{r}-a^{r}} \int_{a}^{b} f(t) t^{r-1} d t \frac{r}{b^{r}-a^{r}} \int_{a}^{b} g(t) t^{r-1} d t,
\end{aligned}
$$

and provided that $f$ is Lebesgue integrable and satisfies the condition $m \leq f(t) \leq M$ for $t \in[a, b]$ and $g:[a, b] \rightarrow \mathbb{R}$ is absolutely continuous on $[a, b]$ and $\ell^{1-r} g^{\prime} \in$ $L_{\infty}[a, b]$.

If $f, g:[a, b] \rightarrow \mathbb{R}$ are absolutely continuous on $[a, b]$ and $\ell^{1-r} f^{\prime}, \ell^{1-r} g^{\prime} \in$ $L_{\infty}[a, b]$, then by $(2.7)$ we have

$$
\left|C_{r \ell^{r-1}}(f, g)\right| \leq \frac{1}{12}\left\|\ell^{1-r} f^{\prime}\right\|_{[a, b], \infty}\left\|\ell^{1-r} g^{\prime}\right\|_{[a, b], \infty}\left(b^{r}-a^{r}\right)^{2} .
$$

Also, if $f, g:[a, b] \rightarrow \mathbb{R}$ are absolutely continuous on $[a, b]$ and $\ell^{\frac{1-r}{2}} f^{\prime}, \ell^{\frac{1-r}{2}} g^{\prime} \in$ $L_{2}[a, b]$, then we have by $(2.10)$ that

$$
\left|C_{r \ell^{r-1}}(f, g)\right| \leq \frac{1}{\pi^{2}}\left\|\ell^{\frac{1-r}{2}} f^{\prime}\right\|_{[a, b], 2}\left\|\ell^{\frac{1-r}{2}} g^{\prime}\right\|_{[a, b], 2}\left(b^{r}-a^{r}\right) .
$$

\section{Applichtions for Probability Density Functions}

The above result can be extended for infinite intervals $I$ by assuming that the function $f: I \rightarrow \mathbb{C}$ is locally absolutely continuous on $I$.

For instance, if $I=[a, \infty), w(s)>0$ for $s \in[a, \infty)$ with $\int_{a}^{\infty} w(s) d s=1$, namely $w$ is a probability density function on $[a, \infty), f$ is Lebesgue measurable and satisfies 
the condition $m \leq f(t) \leq M$ for $t \in[a, \infty)$ and $g:[a, \infty) \rightarrow \mathbb{R}$ is locally absolutely continuous on $[a, \infty)$ with $\frac{g^{\prime}}{w} \in L_{\infty}[a, \infty)$, then by considering the functional

$$
C_{w}(f, g):=\int_{a}^{\infty} w(t) f(t) g(t) d t-\int_{a}^{\infty} w(t) f(t) d t \int_{a}^{\infty} w(t) g(t) d t
$$

we have from (2.2) that

$$
\left|C_{w}(f, g)\right| \leq \frac{1}{8}(M-m)\left\|\frac{g^{\prime}}{w}\right\|_{[a, \infty), \infty} .
$$

Moreover, if $\frac{f^{\prime}}{w} \in L_{\infty}[a, \infty)$ then also by $(2.7)$

$$
\left|C_{w}(f, g)\right| \leq \frac{1}{12}\left\|\frac{f^{\prime}}{w}\right\|_{[a, \infty), \infty}\left\|\frac{g^{\prime}}{w}\right\|_{[a, \infty), \infty} .
$$

If $\frac{f^{\prime}}{w^{1 / 2}}, \frac{g^{\prime}}{w^{1 / 2}} \in L_{2}[a, \infty)$, then we have by $(2.10)$

$$
\left|C_{w}(f, g)\right| \leq \frac{1}{\pi^{2}}\left\|\frac{f^{\prime}}{w^{1 / 2}}\right\|_{[a, \infty), 2}\left\|\frac{g^{\prime}}{w^{1 / 2}}\right\|_{[a, \infty), 2} .
$$

In probability theory and statistics, the beta prime distribution (also known as inverted beta distribution or beta distribution of the second kind) is an absolutely continuous probability distribution defined for $x>0$ with two parameters $\alpha$ and $\beta$, having the probability density function:

$$
w_{\alpha, \beta}(x):=\frac{x^{\alpha-1}(1+x)^{-\alpha-\beta}}{B(\alpha, \beta)}
$$

where $B$ is Beta function

$$
B(\alpha, \beta):=\int_{0}^{1} t^{\alpha-1}(1-t)^{\beta-1}, \alpha, \beta>0 .
$$

The cumulative distribution function is

$$
W_{\alpha, \beta}(x)=I_{\frac{x}{1+x}}(\alpha, \beta),
$$

where $I$ is the regularized incomplete beta function defined by

$$
I_{z}(\alpha, \beta):=\frac{B(z ; \alpha, \beta)}{B(\alpha, \beta)} .
$$

Here $B(\cdot ; \alpha, \beta)$ is the incomplete beta function defined by

$$
B(z ; \alpha, \beta):=\int_{0}^{z} t^{\alpha-1}(1-t)^{\beta-1}, \alpha, \beta, z>0 .
$$

Consider the functional

$$
\begin{aligned}
C_{B, \alpha, \beta}(f, g):=B & (\alpha, \beta) \int_{0}^{\infty} t^{\alpha-1}(1+t)^{-\alpha-\beta} f(t) g(t) d t \\
& -\int_{0}^{\infty} t^{\alpha-1}(1+t)^{-\alpha-\beta} f(t) d t \int_{0}^{\infty} t^{\alpha-1}(1+t)^{-\alpha-\beta} g(t) d t
\end{aligned}
$$

where $\alpha, \beta>0$.

Therefore, by (3.1)-(3.3) we have for $\ell(t)=t$, that

$$
\left|C_{B, \alpha, \beta}(f, g)\right| \leq \frac{1}{8}(M-m) B^{3}(\alpha, \beta)\left\|g^{\prime} \ell^{1-\alpha}(1+\ell)^{\alpha+\beta}\right\|_{[0, \infty), \infty}
$$


provided $m \leq f(t) \leq M$ for $t \in[0, \infty)$ and $g^{\prime} \ell^{1-\alpha}(1+\ell)^{\alpha+\beta} \in L_{\infty}[0, \infty)$,

$$
\begin{aligned}
& \left|C_{B, \alpha, \beta}(f, g)\right| \\
& \quad \leq \frac{1}{12} B^{4}(\alpha, \beta)\left\|f^{\prime} \ell^{1-\alpha}(1+\ell)^{\alpha+\beta}\right\|_{[0, \infty), \infty}\left\|g^{\prime} \ell^{1-\alpha}(1+\ell)^{\alpha+\beta}\right\|_{[0, \infty), \infty} ;
\end{aligned}
$$

provided $f^{\prime} \ell^{1-\alpha}(1+\ell)^{\alpha+\beta}, g^{\prime} \ell^{1-\alpha}(1+\ell)^{\alpha+\beta} \in L_{\infty}[0, \infty)$ and

$$
\begin{aligned}
& \left|C_{B, \alpha, \beta}(f, g)\right| \\
& \quad \leq \frac{1}{\pi^{2}} B^{3}(\alpha, \beta)\left\|f^{\prime} \ell^{\frac{1-\alpha}{2}}(1+\ell)^{\frac{\alpha+\beta}{2}}\right\|_{[0, \infty), 2}\left\|g^{\prime} \ell^{\frac{1-\alpha}{2}}(1+\ell)^{\frac{\alpha+\beta}{2}}\right\|_{[0, \infty), 2} ;
\end{aligned}
$$

provided $f^{\prime} \ell^{\frac{1-\alpha}{2}}(1+\ell)^{\frac{\alpha+\beta}{2}}, g^{\prime} \ell^{\frac{1-\alpha}{2}}(1+\ell)^{\frac{\alpha+\beta}{2}} \in L_{2}[0, \infty)$.

Similar results may be stated for the probability distributions that are supported on the whole axis $\mathbb{R}=(-\infty, \infty)$. Namely, if $I=(-\infty, \infty), f: \mathbb{R} \rightarrow \mathbb{C}$ is locally absolutely continuous on $\mathbb{R}$ and $w(s)>0$ for $s \in \mathbb{R}$ with $\int_{-\infty}^{\infty} w(s) d s=1$, namely $w$ is a probability density function on $(-\infty, \infty), f$ is Lebesgue measurable and satisfies the condition $m \leq f(t) \leq M$ for $t \in(-\infty, \infty)$ and $g:(-\infty, \infty) \rightarrow \mathbb{R}$ is locally absolutely continuous on $(-\infty, \infty)$ with $\frac{g^{\prime}}{w} \in L_{\infty}(-\infty, \infty)$, then, by considering the functional

$$
C_{w}(f, g):=\int_{-\infty}^{\infty} w(t) f(t) g(t) d t-\int_{-\infty}^{\infty} w(t) f(t) d t \int_{-\infty}^{\infty} w(t) g(t) d t,
$$

we have

$$
\left|C_{w}(f, g)\right| \leq \frac{1}{8}(M-m)\left\|\frac{g^{\prime}}{w}\right\|_{(-\infty, \infty), \infty} .
$$

Moreover, if $\frac{f^{\prime}}{w} \in L_{\infty}(-\infty, \infty)$ then also

$$
\left|C_{w}(f, g)\right| \leq \frac{1}{12}\left\|\frac{f^{\prime}}{w}\right\|_{(-\infty, \infty), \infty}\left\|\frac{g^{\prime}}{w}\right\|_{(-\infty, \infty), \infty} .
$$

If $\frac{f^{\prime}}{w^{1 / 2}}, \frac{g^{\prime}}{w^{1 / 2}} \in L_{2}(-\infty, \infty)$, then we have

$$
\left|C_{w}(f, g)\right| \leq \frac{1}{\pi^{2}}\left\|\frac{f^{\prime}}{w^{1 / 2}}\right\|_{(-\infty, \infty), 2}\left\|\frac{g^{\prime}}{w^{1 / 2}}\right\|_{(-\infty, \infty), 2} .
$$

In what follows we give an example.

The probability density of the normal distribution on $(-\infty, \infty)$ is

$$
w_{\mu, \sigma^{2}}(x):=\frac{1}{\sqrt{2 \pi} \sigma} \exp \left(-\frac{(x-\mu)^{2}}{2 \sigma^{2}}\right), x \in \mathbb{R},
$$

where $\mu$ is the mean or expectation of the distribution (and also its median and mode), $\sigma$ is the standard deviation, and $\sigma^{2}$ is the variance.

The cumulative distribution function is

$$
W_{\mu, \sigma^{2}}(x)=\frac{1}{2}+\frac{1}{2} \operatorname{erf}\left(\frac{x-\mu}{\sigma \sqrt{2}}\right),
$$

where the error function erf is defined by

$$
\operatorname{erf}(x)=\frac{2}{\sqrt{\pi}} \int_{0}^{x} \exp \left(-t^{2}\right) d t .
$$


Consider the functional

$$
\begin{aligned}
C_{N, \sigma, \mu}(f, g):= & \sqrt{2 \pi} \sigma \int_{-\infty}^{\infty} \exp \left(-\frac{(t-\mu)^{2}}{2 \sigma^{2}}\right) f(t) g(t) d t \\
& -\int_{-\infty}^{\infty} \exp \left(-\frac{(t-\mu)^{2}}{2 \sigma^{2}}\right) f(t) d t \int_{-\infty}^{\infty} \exp \left(-\frac{(t-\mu)^{2}}{2 \sigma^{2}}\right) g(t) d t
\end{aligned}
$$

with the parameters $\mu$ and $\sigma$ as above.

Therefore, by (3.7)-(3.9) we have

$$
\left|C_{N, \sigma, \mu}(f, g)\right| \leq \frac{1}{8}(M-m)(\sqrt{2 \pi} \sigma)^{3}\left\|g^{\prime} \exp \left(\frac{(\ell-\mu)^{2}}{2 \sigma^{2}}\right)\right\|_{(-\infty, \infty), \infty} ;
$$

provided $m \leq f(t) \leq M$ for $t \in(-\infty, \infty)$ and $g^{\prime} \exp \left(\frac{(\ell-\mu)^{2}}{2 \sigma^{2}}\right) \in L_{\infty}(-\infty, \infty)$.

Moreover, if $f^{\prime} \exp \left(\frac{(\ell-\mu)^{2}}{2 \sigma^{2}}\right) \in L_{\infty}(-\infty, \infty)$ then also

$$
\leq \frac{1}{12}(\sqrt{2 \pi} \sigma)^{4}\left\|f^{\prime} \exp \left(\frac{(\ell-\mu)^{2}}{2 \sigma^{2}}\right)\right\|_{(-\infty, \infty), \infty}\left\|g^{\prime} \exp \left(\frac{(\ell-\mu)^{2}}{2 \sigma^{2}}\right)\right\|_{(-\infty, \infty), \infty} .
$$

If $f^{\prime} \exp \left(\frac{(\ell-\mu)^{2}}{2 \sigma^{2}}\right), g^{\prime} \exp \left(\frac{(\ell-\mu)^{2}}{2 \sigma^{2}}\right) \in L_{2}(-\infty, \infty)$, then we have

$$
\leq \frac{1}{\pi^{2}}(\sqrt{2 \pi} \sigma)^{3}\left\|f^{\prime} \exp \left(\frac{(\ell-\mu)^{2}}{2 \sigma^{2}}\right)\right\|_{(-\infty, \infty), 2}\left\|g^{\prime} \exp \left(\frac{(\ell-\mu)^{2}}{2 \sigma^{2}}\right)\right\|_{(-\infty, \infty), 2} .
$$

\section{REFERENCES}

[1] M. W. Alomari, A companion of Grüss type inequality for Riemann-Stieltjes integral and applications. Mat. Vesnik 66 (2014), no. 2, 202-212.

[2] D. Andrica and C. Badea, Grüss' inequality for positive linear functionals. Period. Math. Hungar. 19 (1988), no. 2, 155-167.

[3] D. Baleanu, S. D. Purohit and F. Uçar, On Grüss type integral inequality involving the Saigo's fractional integral operators. J. Comput. Anal. Appl. 19 (2015), no. 3, 480-489

[4] P. L. Chebyshev, Sur les expressions approximatives des intègrals dèfinis par les outres prises entre les même limites, Proc. Math. Soc. Charkov, 2 (1882), 93-98.

[5] P. Cerone, On a Čebyšev-type functional and Grüss-like bounds. Math. Inequal. Appl. 9 (2006), no. 1, 87-102.

[6] P. Cerone and S. S. Dragomir, A refinement of the Grüss inequality and applications, Tamkang J. Math., 38(1) (2007), 37-49. Preprint RGMIA Res. Rep. Coll., 5(2) (2002), Article 14. [ONLINE: http://rgmia.vu.edu.au/v5n2.html].

[7] P. Cerone and S. S. Dragomir, Some new Ostrowski-type bounds for the Čebyšev functional and applications. J. Math. Inequal. 8 (2014), no. 1, 159-170.

[8] P. Cerone, S. S. Dragomir and J. Roumeliotis, Grüss inequality in terms of $\Delta$-seminorms and applications. Integral Transforms Spec. Funct. 14 (2003), no. 3, 205-216.

[9] S. S. Dragomir, A generalization of Grüss's inequality in inner product spaces and applications. J. Math. Anal. Appl. 237 (1999), no. 1, 74-82.

[10] S. S. Dragomir, A Grüss' type integral inequality for mappings of $r$-Hölder's type and applications for trapezoid formula. Tamkang J. Math. 31 (2000), no. 1, 43-47.

[11] S. S. Dragomir, Some integral inequalities of Grüss type. Indian J. Pure Appl. Math. 31 (2000), no. 4, 397-415. 
[12] S. S. Dragomir, Integral Grüss inequality for mappings with values in Hilbert spaces and applications. J. Korean Math. Soc. 38 (2001), no. 6, 1261-1273.

[13] S. S. Dragomir, A Grüss related integral inequality and applications. Nonlinear Anal. Forum 8 (2003), no. 1, 79-92.

[14] S. S. Dragomir and I. A. Fedotov, An inequality of Grüss' type for Riemann-Stieltjes integral and applications for special means. Tamkang J. Math. 29 (1998), no. 4, 287-292.

[15] S. S. Dragomir and I. Gomm, Some integral and discrete versions of the Grüss inequality for real and complex functions and sequences. Tamsui Oxf. J. Math. Sci. 19 (2003), no. 1, $67-77$.

[16] A. M. Fink, A treatise on Grüss' inequality. Analytic and Geometric Inequalities and Applications, 93-113, Math. Appl., 478, Kluwer Acad. Publ., Dordrecht, 1999.

[17] G. Grüss, Über das Maximum des absoluten Betrages von $\frac{1}{b-a} \int_{a}^{b} f(x) g(x) d x-$ $\frac{1}{(b-a)^{2}} \int_{a}^{b} f(x) d x \int_{a}^{b} g(x) d x$, Math. Z., 39(1935), 215-226.

[18] D. Jankov Maširević and T. K. Pogány, Bounds on Čebyšev functional for $C_{\varphi}[0,1]$ function class. J. Anal. 22 (2014), 107-117.

[19] Z. Liu, Refinement of an inequality of Grüss type for Riemann-Stieltjes integral. Soochow J. Math. 30 (2004), no. 4, 483-489.

[20] Z. Liu, Notes on a Grüss type inequality and its application. Vietnam J. Math. 35 (2007), no. $2,121-127$.

[21] A. Lupaş, The best constant in an integral inequality, Mathematica (Cluj, Romania), 15(38)(2) (1973), 219-222.

[22] A. Mc.D. Mercer and P. R. Mercer, New proofs of the Grüss inequality. Aust. J. Math. Anal. Appl. 1 (2004), no. 2, Art. 12, 6 pp.

[23] N. Minculete and L. Ciurdariu, A generalized form of Grüss type inequality and other integral inequalities. J. Inequal. Appl. 2014, 2014:119, 18 pp.

[24] A. M. Ostrowski, On an integral inequality, Aequat. Math., 4 (1970), 358-373.

[25] B. G. Pachpatte, A note on some inequalities analogous to Grüss inequality. Octogon Math. Mag. 5 (1997), no. 2, 62-66

[26] J. Pečarić and Š. Ungar, On a inequality of Grüss type. Math. Commun. 11 (2006), no. 2, $137-141$.

[27] M. Z. Sarikaya and H. Budak, An inequality of Grüss like via variant of Pompeiu's mean value theorem. Konuralp J. Math. 3 (2015), no. 1, 29-35.

[28] N. Ujević, A generalization of the pre-Grüss inequality and applications to some quadrature formulae. J. Inequal. Pure Appl. Math. 3 (2002), no. 1, Article 13, 9 pp.

${ }^{1}$ Mathematics, College of Engineering \& Science, Victoria University, PO Box 14428, Melbourne City, MC 8001, Australia.

E-mail address: sever.dragomir@vu.edu.au

$U R L:$ http://rgmia.org/dragomir

${ }^{2}$ DSt-nRF Centre of Excellence in the Mathematical, and Statistical Sciences, School of Computer Science, \& Applied Mathematics, University of the WitwaterSrand, Private Bag 3, Johannesburg 2050, South Africa 